\section{Uma visão altiva da periferia}

Samuel PINHEIRO GUIMARÃES. Desafios brasileiros na era dos gigantes. Rio de Janeiro, Contraponto, 2006. 455 páginas.

\section{Amâncio Jorge de Oliveira Janina Onuki}

As razões que explicariam a inserção internacional subordinada de um país como o Brasil, periférico, porém com cacife suficiente para se posicionar de forma autônoma e altiva no concerto das nações - haja vista o potencial geográfico e econômico -, consistem em um dos mais relevantes temas das relações internacionais contemporâneas. Uma das linhas explicativas, e talvez a mais recorrente, é de cunho determinista: o padrão de inserção dos países da periferia é fruto de constrangimentos do sistema e não de opções políticas autônomas. O corolário desse tipo de formulação analítica seria, no plano concreto das políticas externas, orientações conformistas e subordinadas, sem brechas para ousadia.

O interesse nacional, nesta vertente pessimista, seria forjado no marco de uma percepção subordinada que o próprio país teria da sua posição no sistema internacional, de forma que realidade e subjetividade seriam mutuamente constitutivas. "Somos periféricos", logo, só nos resta "ter" uma política externa periférica. A condição de periferia é, segundo esse esquema analítico, conseqüência e causa da condição de subordinação. A sensação de impotência ante os poucos gigantes que dominam o sistema internacional particularmente os Estados Unidos - tenderia a justificar a desigualdade e sua ampliação entre os países desenvolvidos e os em desenvolvimento.

O objetivo deste livro do embaixador Samuel Pinheiro Guimarães, Secretário-Geral do Ministério de Relações Exteriores e segundo homem na hierarquia da instituição, é abrir um confronto direto contra tais teses deterministas, que apontam para um intercâmbio inexorável entre "situação periférica" e "atuação periférica".

O confronto é feito tanto no plano das premissas estruturadoras da situação do país no siste- ma internacional como no plano de padrão de política externa a ser adotado. Assim, o livro, certamente em decorrência da formação acadêmica do autor e da sua condição de operador da alta política brasileira, comporta a um só tempo as dimensões analítica e normativa, e oferece descrição e prescrição no campo da política internacional.

No âmbito analítico, Desafios brasileiros na era dos gigantes não se propõe a negar a existência das profundas assimetrias e concentração de poder que regem o sistema internacional. Diverge, contudo, das teses deterministas, na medida em que atenta para o fato de que um dos braços da dominação hegemônica é precisamente a autopercepção de inferioridade, que imobiliza e faz reiterar a própria dominação. Nesse contexto, a saída para o Brasil reside em superar esse círculo vicioso por meio de ação política assertiva. Para tanto, o autor sugere uma postura internacional mais altiva e contestatória do sistema internacional assimétrico em que estamos inseridos. Cabe contestar não apenas a concentração de poder no plano externo, mas também a concentração de poder no âmbito interno, responsável pela ausência de uma política industrial e tecnológica produzida e sustentada com capital nacional.

O livro faz uma ampla radiografia do Brasil, mostrando tanto as deficiências históricas do capitalismo brasileiro que, ainda hoje, comprometem o desenvolvimento econômico do país, como também as potencialidades e a responsabilidade que nos cabe na mudança do cenário econômico internacional, a fim de torná-lo mais favorável aos países periféricos. Ou seja, para além da determinação histórica, o autor atribui um peso-chave às escolhas políticas dos governantes, que, caso sejam equivocadas como foram em gestões passadas, ampliam a situação de subordinação e vulnerabilidade do país.

A interpretação de Guimarães, de que a política externa deve ter reflexos no plano interno, é complementada pela avaliação dos problemas domésticos que delimitam nossas vulnerabilidades externas.

Elevado à condição de um dos principais ideólogos da política externa do governo Lula, o autor afirma que as razões para a inserção internacional limitada do Brasil devem ser buscadas não só no exterior, mas também no plano domés- 
tico. Em outras palavras, a possibilidade de contestar as grandes potências decorre tanto da situação favorável criada pela conjuntura internacional, como da postura do Executivo assumida desde 2003. Ou seja, de uma ação política assertiva. Trata-se de uma visão de mundo de um governo que tem origem na periferia, e não nas mudanças construídas ao longo dos últimos anos, que faz deste momento "uma novidade histórica extraordinária", capaz de marcar a posição do Brasil (e de seus vizinhos sul-americanos) como um novo pólo de poder no sistema internacional.

As razões que explicam a dificuldade atual de inserção externa do Brasil podem ser encontradas em nossos antecedentes históricos, marcados por um modelo de dependência e exploração. Mas também são explicadas pelas decisões equivocadas tomadas pelos governos na década de 1990.

Nos primeiros capítulos, o autor dedica-se a uma revisão sistemática da história política e do desenvolvimento econômico do Brasil, buscando identificar vários momentos explicativos da gênese das atuais disparidades internas, da despolitização da sociedade e da sua falta de capacidade em se mobilizar contra o conjunto de desigualdades.

Guimarães constrói sua análise por meio de dicotomias fortes, das quais as mais importantes são "soberania versus subordinação" e "centro versus periferia", ambas fundamentais para se entender o processo de exclusão no qual o Brasil está inserido. Além dessas e de outras dicotomias elencadas pelo autor, vale mencionar uma que permeia todo o trabalho: a divisão entre países "normalistas" ou "normais" do sistema internacional e os "contestadores" da ordem, localizando o Brasil do governo Lula nesta última categoria.

O contraste, exponenciado pelo autor, embute, a um só tempo, a força e a fraqueza do livro. A fraqueza reside no fato de que tal maniqueísmo - útil e responsivo ao período bipolar da Guerra Fria - não tem a mesma validade nos tempos atuais. Estratégias, possibilidades, classificações são mais matizadas diante da dificuldade em se categorizar atualmente os países desenvolvidos ou não desenvolvidos, sob qualquer parâmetro considerado (econômico, social, militar etc.). Em contrapartida, essas mesmas dicotomias ajudam, por meio de contraste, a esclarecer as tensões em jogo no processo de formulação de política externa e seus reflexos na dinâmica atual.
Parte das explicações das desigualdades internas que ainda permanecem no país é explicada pela nossa origem histórica de país colonizado, e que se perpetuou ao longo da nossa trajetória política. A formação do Brasil a partir de um regime dominado por grupos minoritários dificultou não apenas o investimento, mas também a construção de uma cultura necessária à expansão do capital nacional, entendida, pelo autor, como central para a construção de um parque industrial nacional e para criação de conhecimento e de tecnologias próprias.

Na visão de Guimarães, isso parece ser um círculo vicioso: a concentração de poder leva à manutenção de grupos dominantes, que constroem ideologias para manter a dominação, o que impede o país de ter vida própria e caminhar para a estruturação de uma política nacional de desenvolvimento. Ideologias fundamentais que marcam a cultura da sociedade brasileira, definidas pelas denominações de "cordialidade, igualdade racial, do jeitinho", na verdade justificam os privilégios que permanecem no nosso sistema político e em nossa sociedade, acostumados que estamos a importar modelos de fora, e pouco atentos para a "vulnerabilidade ideológica" a que ficamos submetidos.

De outro lado, a inserção internacional deficitária do Brasil pode também ser conseqüência dos equívocos das políticas adotadas ao longo dos anos de 1990, que apenas serviram para aprofundar a subordinação e impedir a implementação de políticas ativas de desenvolvimento.

Guimarães não poupa os governos anteriores pelos diversos dos erros cometidos sob a égide do neoliberalismo e da concepção de "país emergente". A falsa ilusão de que a liberalização da economia, respaldada pela OMC, e a adesão a regimes internacionais com ênfase em temas globais seriam a marca de uma nova agenda externa definiu uma política que exagerou nas concessões (econômicas e políticas) sem obter reciprocidade a favor de nenhum dos nossos interesses.

Foi sob o "fascínio liberal", que prevaleceu entre 1990 e 1999, que foram feitas as propostas de negociações da Alca (Área de Livre-Comércio das Américas) e com a União Européia. A visão equivocada da dinâmica do sistema internacional fez com que essas negociações se estendessem, sem que os governos anteriores se dessem conta 
que estes acordos, tal como estavam sendo propostos, retiravam a relevância dos países periféricos e mantinham as mesmas características assimétricas das negociações internacionais.

No Capítulo 8, o autor contesta o argumento da "diplomacia moderna", segundo o qual a melhor estratégia para um país como o Brasil seria a sua apresentação na esfera internacional como um "país normal". Isso significou a manutenção de uma postura de cumpridor das normas internacionais e de interlocutor privilegiado junto às grandes potências. Mas, em contrapartida, impediu não só a definição autônoma de uma estratégia de inserção internacional, mas também o poder de contestar a estrutura concentrada do sistema internacional, além do que não abriu espaço para que o país superasse suas vulnerabilidades, nem desenvolvesse seu potencial.

Entretanto, embora tenha sido um caminho tortuoso, que ampliou as disparidades internas e externas, o autor aponta saídas que só podem ser encontradas com base na cooperação: "não há solução individual para nenhum país da América do Sul". Trata-se de uma idéia ambiciosa: "a ascensão brasileira à condição de grande potência deve ser vista como objetivo nacional necessário". E nesse contexto caberia contestar a estrutura do sistema internacional, e não se portar apenas como um "país normal".

Cooperação implica assumir responsabilidades para com os países vizinhos, particularmente pelo fortalecimento da relação bilateral com a Argentina. Em princípio, trata-se de modificar a estrutura internacional desigual que prevalece hoje, transformando o sistema mundial em multipolar, "no qual a América do Sul venha a se constituir um dos pólos".

A ênfase na recuperação da relação entre Brasil e Argentina, no contexto do Mercosul, justifica-se perante as críticas ao modelo de integração aberta adotado pelos governos neoliberais que abandonaram a bem-sucedida cooperação que vinha avançando desde os anos de 1980. A proposta central do atual governo é transformar o Mercosul num "esquema de desenvolvimento econômico regional", criando um programa estratégico e uma política externa comum, sem qualquer pretensão hegemônica por parte do Brasil.

As críticas à instabilidade do bloco, provocada pelas divergências entre os países e pelos parcos resultados obtidos, foram enfrentadas pelo embaixador Guimarães com extremo otimismo. Coube ao Brasil, a partir de 2003, estabelecer uma visão pragmática do mundo e definir estratégias de confrontação às grandes potências (que sempre atribuíram o papel de "colônia moderna" aos países da América do Sul), com os objetivos de reduzir as disparidades sociais internas e ampliar a capacidade de inserção internacional da região.

Desafios brasileiros na era dos gigantes faz uma espécie de "profissão de fé" no potencial da sociedade brasileira e no desenvolvimento do país com base no enfrentamento (possível) de quatro grandes desafios, sintetizados no último capítulo, mas que permeiam todo o livro: "a eliminação das vulnerabilidades externas; a preservação da autonomia do Estado; a promoção sistemática da multipolarização do sistema mundial; e a construção de um pólo sul-americano".

Fazem parte das principais estratégias brasileiras nesse caminho, segundo o autor, a consolidação do Mercosul, da Comunidade Sul-Americana de Nações e a reforma do Conselho de Segurança da ONU, contribuindo para a democratização das relações internacionais.

Trata-se de definir como objetivo da política externa brasileira a busca, em conjunto com os países do Mercosul e da América do Sul, de uma posição cada vez mais importante no contexto do sistema econômico e político internacional, sem aceitar uma situação de "soberania de segunda classe". A responsabilidade do Brasil revela-se na sua liderança regional, afirmada no governo atual, e na capacidade (e coragem inédita) de desafiar os "gigantes".

Já está claro que este trabalho não é, nem pretende ser, imparcial. Ao contrário, trava uma luta aberta, tanto de idéias como de ação, no campo da política externa brasileira. Contudo, é possível garantir que os leitores tomarão contato com um pensamento sistemático e coerente, que forma um mapa abrangente de uma concepção de política externa tributária do pensamento cepalino.

\footnotetext{
AMÂNCIO JORGE DE OLIVEIRA é professor do Departamento de Ciência Política da USP e coordenador científico do Centro de Estudos das Negociações Internacionais (Caeni-USP).
} 
JANINA ONUKI é professora de Relações

Internacionais da Unesp e pesquisadora do Caeni-USP. 